\author{
황해에 분포하는 살오징어의 음향산란강도 특성 및 \\ 분포밀도 추정 \\ 이경훈 ${ }^{\star} \cdot$ 최정화' - 신종근 ${ }^{2}$ 장대수 $\cdot$ 박성욱
}

국립수산과학원 수산공학과, ${ }^{1}$ 국립수산과학원 자원연구과, ${ }^{2}$ 국립수산과학원 연구기획과

\title{
Acoustical backscattering strength characteristics and density estimates of Japanese common squid distributed in Yellow Sea
}

\author{
Kyoung-Hoon LeE*, Jung-Hwa CHOI ${ }^{1}$, Jong-Keun SHIN ${ }^{2}$, Dae-Soo CHANG ${ }^{1}$ \\ and Seong-Wook PARK \\ Fisheries Engineering Division, National Fisheries Research \& Development Institute, \\ Busan 619-705, Korea \\ ${ }^{1}$ Resources Research Division, NFRDI, Busan 619-705, Korea \\ ${ }^{2}$ Research \& Development Planning Division, NFRDI, Busan 619-705, Korea
}

\begin{abstract}
Due to change of various marine environments according to seawater temperature rising, Japanese common squid(Todarodes pacificus), which was distributed in East Sea, was recently caught in Yellow Sea during a summer season from 2006. The fishery resources density research was carried out in Korea-China Provisional Water Zone using trawl fishing gear and acoustics in National Fisheries Research \& Development Institute in Korea. This paper showed the analysis on the acoustical backscattering strength by two frequencies $(38 \mathrm{kHz}, 120 \mathrm{kHz})$ for Japanese common squid by acoustical scattering theoretical model based on size distribution for survey period, and estimate the density distribution for squid' s integrated layer which was extracted from any scatterers distributed in water column using two frequency difference method which has been used to distinguish fish shoals or specific target scatterers from sound scattering layer which is composed of various zooplankton. Furthermore, the entire range of their density estimation was suggested using by Monte Carlo simulation under considering each uncertainty such as size distributions or swimming angle and so on in survey area.
\end{abstract}

Key words : Japanese common squid, Todarodes pacificus, Acoustical scattering theoretical model, DWBA, Density estimates

\footnotetext{
*Corresponding author: khlee71@nfrdi.go.kr, Tel:82-51-720-2571, Fax:82-51-720-2586
} 
서 론

살오징 어(Japanese common squid, Todarodes pacificus)는 1991 년부터 채낚기어업 및 트롤어 업을 중심으로 연간 10 만톤 이상의 어획량을 유 지 하고 있는 우리나라 주요 상업어종이며, 일본 에서는 1998 년 부터 TAC(Total Allowable Catch) 어종으로 채택되어 관리하고 있으며, 우리나라 에서도 2007년부터 TAC 관리대상어종으로 채 택하여 주요 업종인 근해채낚기, 동해구트롤, 대 형선망, 대형트롤 어 업을 대상으로 주변해역에 분포하는 살오징어의 어획량을 배정하여 관리 하고 있다.

$\mathrm{TAC}$ 에 의한 어족자원의 관리는 어업인 의 어 획 실적이나 어선 규모에 따른 어선별 할당량과 관련된 과학적인 자원평 가를 바탕으로 결정되 는데, 살오징어의 자원량을 추정하기 위 하여 트 롤조사나 채 낚기 어업 등의 CPUE(단위노력당어 획 량)에 의해 행해지고 있으나, 실 질적인 자원 관리방법으로 지표를 제시하기에는 문제가 있 다. 따라서, 수중에 분 포하는 대 상어 류를 생 태계 에 영항을 최소화하는 방법으로 모니터링이 가 능한 음향기법에서는 현 존 자원량을 추정하기 위하여 살오징어를 대 상으로 개체별 음항산란 특성에 관한 연구사례도 국내 - 외적으로 활발 하게 연구가 진행되고 있다(Goss et al., 2001; Kang et al., 2004; Kawabata, 2005; Lee, 2005).

최근 수온상승에 따른 해양환경의 변화로 인 하여 동해안에서 주로 어획이 되던 살오징어가 하절기에 우리나라서해안해역 에서도 어획되고 있는 실정이므로, 본 연구에서는 음향기법을 이 용한 살오징어 자원량을 조사하기 위한 기초적 인 연 구로서, 한 - 중 잠정조치수역 자원조사 기 간 동안 수행한 조사내용에서 자유 유영 상태의 살오징어에 대한 주퐈수별 음항산란강도 특성 을 규명하고, 현재 어종식 별기법에 널리 적용되 고 있는 주파수차에 의한 방법(Miyashita et al., 1997; Kang et al., 2002)으로 조사해역의 살오징 어로 추정되는 적분층을 추출하여 조사해역별
분포밀 도를 추정하였다.

\section{재료 및 방법}

본 조사는 한 - 중 잠정조치수역 총 10 해구에 대한 부어자원류의 음향자원조사 및 저서자원 의 분포를 위한 저층트롤조사를 위한 목적으로 2007 년 7 월 25 일 부터 8 월 3 일 까지 10 일간 국립 수산과학원 시험조사선 탐 구 호 $(\mathrm{R} / \mathrm{V}, 2,180 \mathrm{G} / \mathrm{T})$ 를 이용하여 실시하였으며, 선 박에 설치되어 있 는 과학어군탐지시 스템(Scientific echo sounder; EK500 and BI500, SIMRAD)에 의해 2 주파수 $(38 \mathrm{kHz}, 120 \mathrm{kHz})$ 에 대한 음향자료를 수집하였으 며, 후처리분석소프트 웨어(EchoView3.0, SonaData)를 이용하여 오징어 분포수층에 관한 자료를 분석하였다. 또한, 조사해역의 연직 수층 별 해 양환경정보를 퐈악하기 위하여 CTD (SBE - 911, Sea-Bird)를 이용하여 수온 및 염 분 을 측정하였다.

음향을 이용하여 수층에 분포하는 살오징어 의 밀 도를 추정하기 위해서는 채집된 표본에 대 한 후방산란강도(Target Strength) 를 결 정해야만

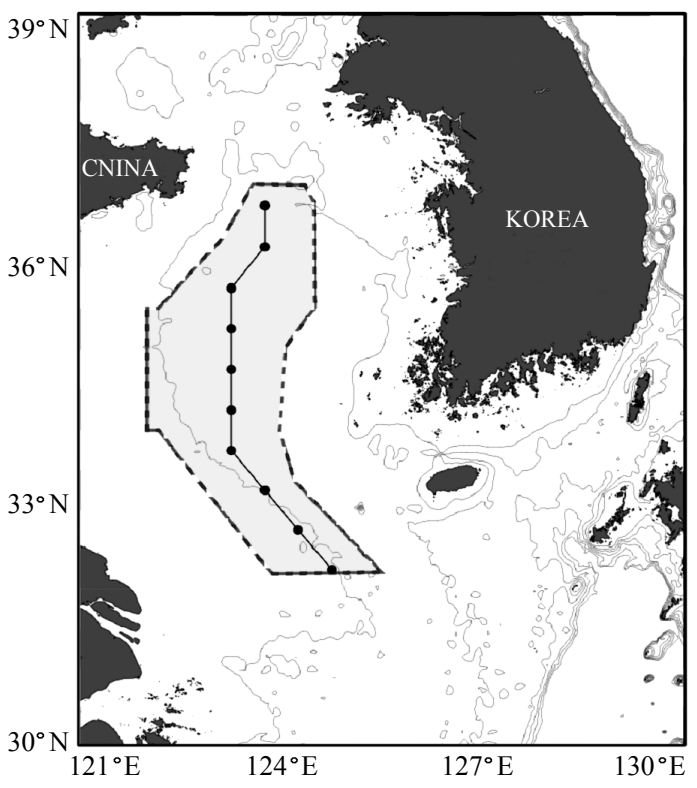

Fig. 1. Survey area(closed circle; haul stations) and Korea-China Provisional Water Zone. 
하는데, 대상생물의 다양한 크기별 음향산란특 성을 규명하기 위하여 현수법(Kang et al., 2004; Kang et al., 2005; Kawabata, 2005; Lee, 2005) 혹은 자유 유영 상태(Goss et al., 2001)에서의 음향신호 를 분석 하여 자원 랑추정 지표로 사용한다. 또한, 음향을 이용하여 어종을 확인하는 방법으로 트 롤이나 채집어구에 의한 어획자료를 하는 것이 기본적인 분석방법으로서, 어획된 오징어를 대 상으로 분포하고 있는 체장조성을 파악하여 분 포수층에 대한 살오징어를 음향산란이론모델인 DWBA(Distorted Wave Born Approximation) 모델 을 이용하여 후방산란강도를 예측할 수 있다.

DWBA 음향산란이 론모 델은 남극 크릴을 변형 실린더 형태로 가정하여 음향산란특성을 분석 하는 방법(McGehee et al., 1998)이 적용되기 시 작하여 유용어류자원의 먹이생 물인 동물플랑크 톤과 같은 소형개체의 후방산란강도를 추정하 기 위한 방법으로 다양한 시 도가 되 었으며, 다중 주파수에 의한 방법(Watkins and Brierley, 2002) 이 적용되면서 다양한 어 종으로부터 주퐈수별 특성을 고려하여 수층에 분포하는 목표종을 분 리하는 방법으로 조사해역의 자원량을 추정하 는데 적용되 고 있다.

우선, 살오징어를 디지타이저 처리한 윤곽 데
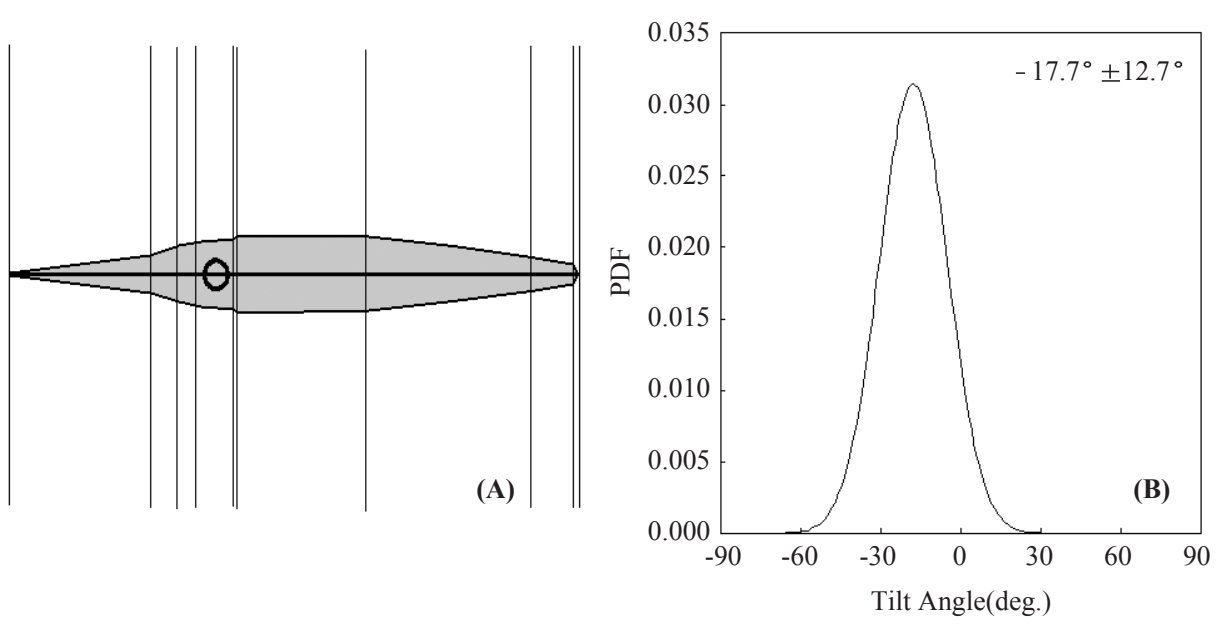

Fig. 2. The shape (A) of Japanese common squid digitized and PDF (B) using swimming tilt angles to estimate theoretical averaged $T S$ values in relation to body length.
이터로부터 3 차원 물체의 음향산란을 변형 실 린 더 형태로 가정하여 다음 식 (1)과 같이 체 적적 분식으로 계산하었다.

$$
f_{b s}=\int_{r_{\mathrm{pos}}} \frac{k_{1}^{2} a}{4 k_{2}}\left(\gamma_{k}-\gamma_{p}\right) e^{2 \mathrm{i} \mathrm{k}_{2} r_{\mathrm{pos}}} \frac{J_{l}\left(2 k_{2} a \cos \beta_{\mathrm{tilt}}\right)}{\cos \beta_{\mathrm{tilt}}}\left|\mathrm{d} r_{\mathrm{pos}}\right| \text { (1) }
$$

여 기서, $k$ 는 음퐈의 퐈수 $\left(\mathrm{m}^{-1}, \mathrm{k}=2 / \lambda\right), \lambda$ 는 퐈장 $(\mathrm{m}, \lambda=c / f) c$ 는 주퐈수 $(\mathrm{m} / \mathrm{sec}), f$ 는 주 퐈수 $(\mathrm{Hz})$ 이다. 아랫 첨자 1 은 주변 매질을, 아랫 첨자 2 는 산란체 의 매질을 나타넨다. $\gamma_{k}$ 와 $\gamma_{p}$ 는 $\gamma_{k}=\left(K_{2}-\right.$ $\left.K_{1}\right) / K_{1}$ 및 $\gamma_{p}=\left(\rho_{2}-\rho_{1}\right) / \rho_{1}$ 로 나타내 는데, $K$ 는 매 질에 대한 압축률 $\left(K=1 / \rho c^{2}\right)$ 로서, $\rho$ 는 체 내 밀 도 $\left(\mathrm{kg} / \mathrm{m}^{3}\right), c$ 는 체 내 음속 $(\mathrm{m} / \mathrm{s})$ 이다. 또한, $\mathrm{a}$ 는 실린 더 단면의 반경 $(\mathrm{m})$ 을, $r_{\mathrm{pos}}$ 는 살오징어를 디지타 이징할 때의 중심선상의 위치벡터 (좌표)이며, tilt는 입사각과 실린더 간의 각도(degree), $J_{1}$ 은 제 1 종 제 1 차 베셀 함수이다.

또한, 살오징어의 3 차원 형태구조는 디지털 사진에 촬영된 개체를 디지타이저 소프트웨어 (GetData Ver. 2.2, Fedorov Software Co.)를 이용 하여 확대, 축소하여 윤곽선을 추출하여 디지타 이 징하였다. $f_{\mathrm{bs}}$ 는 각 실 린더 의 후방산란단면적 $\left(\sigma_{\mathrm{bs}}\right)$ 에 대한 체적적분 계산된 후방산란 진 폭을 나타내며, 단일 개체에 대한 후방산란강도는 아 
이경훈 - 최정화 · 신종근 - 장대수 · 박성욱

Table 1. Equations for density estimates of Japanese common squid in survey area

\begin{tabular}{lll}
\hline Items(unit) & Equations & Remarks \\
\hline Target Strength $(\mathrm{dB})$ & $T S=20 \log _{10}(\mathrm{~L})-73.5$ & Kang et al., 2005 \\
Backscattering cross section $\left(\mathrm{m}^{2}\right)$ & $\sigma=4 \pi 10^{-7.2} \cdot L^{2.0}$ & NFRDI, 2005 \\
Length $(\mathrm{cm})-$ Weight $(\mathrm{g})$ & $w=0.0091 \cdot M L^{3.2472}$ & SonarData, 2000 \\
Density $\left(\mathrm{g} / \mathrm{m}^{2}\right)$ & $\rho=(N A S C / \sigma) \cdot w$ & \\
\hline
\end{tabular}

래 식 (2)와 같이 나타낼 수 있다.

$$
\mathrm{TS}=10 \log _{\mathrm{bs}}^{o_{\mathrm{bs}}}=10 \log \left|f_{\mathrm{bs}}\right|^{2}
$$

여 기서, 음향산란이론모델에 적 용되는 살오징 어 의 밀 도비 와 음속비는 각각 'Density bottle' 법 과 'Time of flight' 법을 이용하여 체내 음속비 (h) 와 밀 도비 $(g)$ 는 각각 1.041 및 1.029 의 값을 적 용(Kang et al., 2006)하여 각 주퐈수별 체 장에 대 한 평균 TS를 추정하었으며, 이론값을 계산하기 위하여 필요한 유영자세각의 확률밀 도함수는 Fig. 2 와 같이 $-17.7^{\circ} \pm 12.7^{\circ}($ Avg. \pm S.D) 를 적 용 하였다(Kang et al., 2005).

$$
\left\langle\sigma_{\mathrm{bs}}\right\rangle=\int_{-90}^{+90} \sigma_{\mathrm{bs}}(\theta) f(\theta) \mathrm{d} \theta
$$

여 기서, $\sigma_{\mathrm{bs}}(\theta)$ 는 각 유영자세각도 $\theta$ 에서의 후 방 산란단면적 을, $f(\theta)$ 는 각 유영자세각도의 출현빈 도를 나타낸 다.

조사해역에서는 다양한 회 유성 어족들이 분포 하며 수층별 음향자료로부터 살오징어에 대한 음향신호를 추출하기 위해 DWBA 모델을 이용 하여 외 투장(M.L)을 고려한 전체 길이에 대한 2 주퐈수 $(38 \mathrm{kHz}, 120 \mathrm{kHz})$ 에 의 한 주퐈수차를 계산 해야 하므로, 음향이론모델에 의해 추정된 살오 징어의 TS의 주퐈수 특성을 적용하였다. 두 주 퐈수 차에 의한 종식별 방법은 대상산란체 의 평 균 체장 $(\bar{L})$ 에 있어서, 평균 $\mathrm{TS}$ 의 주파수 차에 대한 비율이 임 의의 체적에 대한 체 적후방산란 강도 $(\mathrm{SV})$ 의 비율과 동일하다는 것으로 설명이 가능하다.

$$
\begin{aligned}
\text { dBdifference } & =\mathrm{SV}(120 \mathrm{kHz}, \bar{L})-\mathrm{SV}(38 \mathrm{kHz}, \bar{L}) \\
& =\mathrm{TS}(120 \mathrm{kHz}, \bar{L})-\mathrm{TS}(38 \mathrm{kHz}, \bar{L})
\end{aligned}
$$

음향기법을 이용한 조사해역의 살오징어 분 포밀도를 추정하기 위해 조사해역에서 저장된 에코그램에서 주파수차에 의해 살오징어 에코 신호를 추출한 가상 에코그램을 10 마일 간격으 로 얻어진 NASC 값을 살오징어의 TS 값으로 계 산할 수 있으며, 살오징어로 추출된 에코신호는 체장-체 중관계식를 이용하여 Table 1 과 같이 조사해역의 분포밀도를 추정할 수 있다.

\section{결과 및 고찰}

조사해역에 분포하고 있는 살오징어의 분포 수층에 대한 수온. 염분 분포의 경우, 전형적인 수온약층이 Fig. 3 과 같이 수심 $15 \mathrm{~m}$ 에 서 $25 \mathrm{~m}$ 까 지 강하게 형 성되어 있었으며, 음향자료와 어획 수심을 고려한 결과, 오징어는 수심 약 $18 \mathrm{~m}$ 까지 비교적 넓은 수온대 $\left(15-25^{\circ} \mathrm{C}\right)$ 에 분포하고 있 으나, $20 \mathrm{~m}$ 이하의 수온약층 아래 수심대에서는 어 뗘한 오징어의 음향산란신호가 없는 것으로 나타났다. 물론, 오징어 채낚기에 의해 표본채집

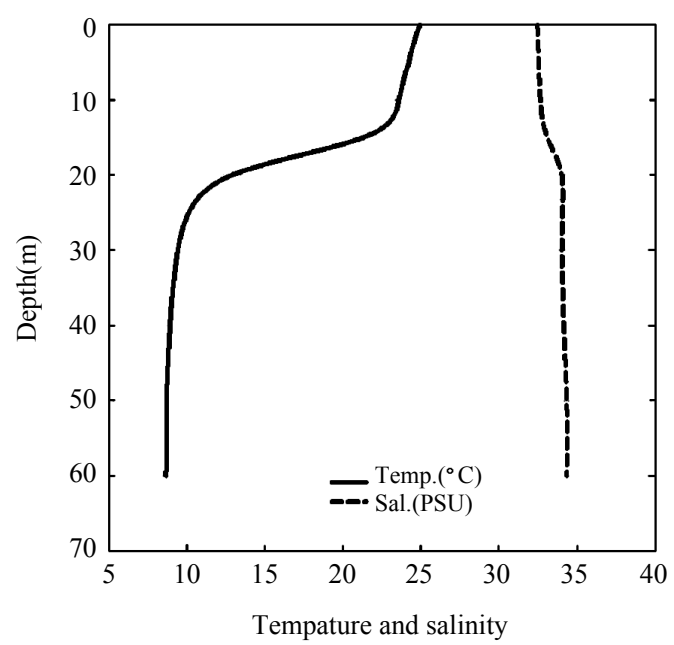

Fig. 3. Temperature and salinity profiles at survey area. 
시기에 는 조사선 박의 조명 효과에 의한 수심별 분포라고 추정할 수 있으나, 적정수온대 수심에 분포하고 있는 것이 가장 타당성이 있는 것으로 사료된다.

또한, 채낚기어구에 의해 어획된 표본채집된 오징어 의 체장조성 결과, 평균 외투장은 $20.9 \mathrm{~cm}(\mathrm{~S} . \mathrm{D}: 1.6)$ 이었다. 살오징어의 크기별 음 향산란특성 을 추정하기 위 한 음항산란모 델에 는 머리부분에서의 10 개 다리부분이 유영할 때 입

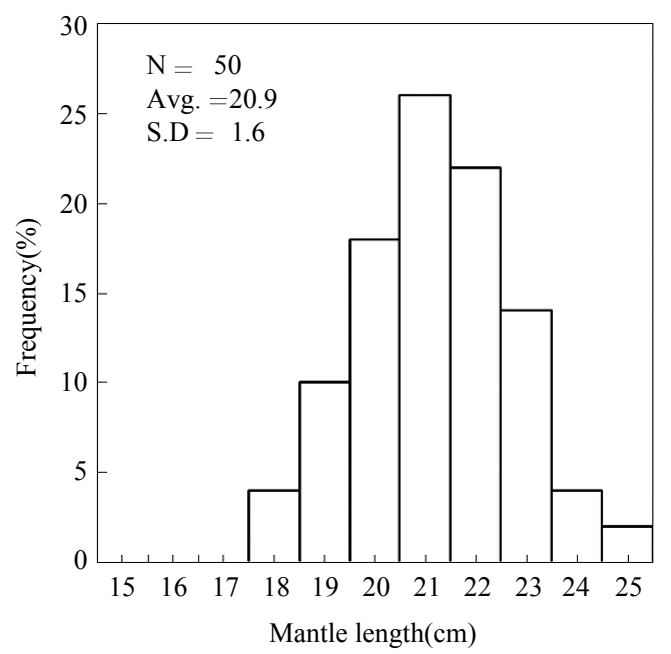

Fig. 4. Mantle length distribution of Japanese common squid.
주위부분의 일직선으로 유지하는 실린더 형상 으로 설 정하고, 살오징어의 외 투장과 전 장의 비 는 T.L =1.6 · M.L(Mukai et al., 2000)를 고려하 였다. 그 결과, $\mathrm{DWBA}$ 모델에 적용한 살오징어 의 평균 전장은 $33.4 \mathrm{~cm}$ 로 설 정하고 최 소 $29.0 \mathrm{~cm}$, 최대 $40.0 \mathrm{~cm}$ 의 분포범위로 하여 음항산란이론 모델에 의해 Fig. 5 와 같이 전장에 대한 평 균 후 방산란강도를 나타내 었으며, 2주퐈수에 대 한 평 균 $\mathrm{TS}$ 함수식으로부터 주퐈수 차는 다음 식 (5) 와 같이 결정하였다.

$-0.01 \mathrm{~dB}<\Delta \mathrm{SV}_{120 \mathrm{kHz}-38 \mathrm{kHz}}<0.64 \mathrm{~dB}$

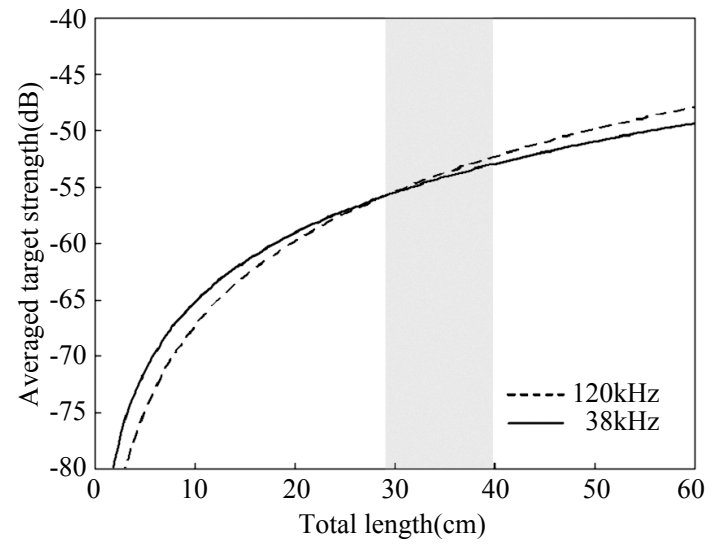

Fig. 5. Averaged Target Strength of Japanese common squid considered with PDF of swimming tilt angle.

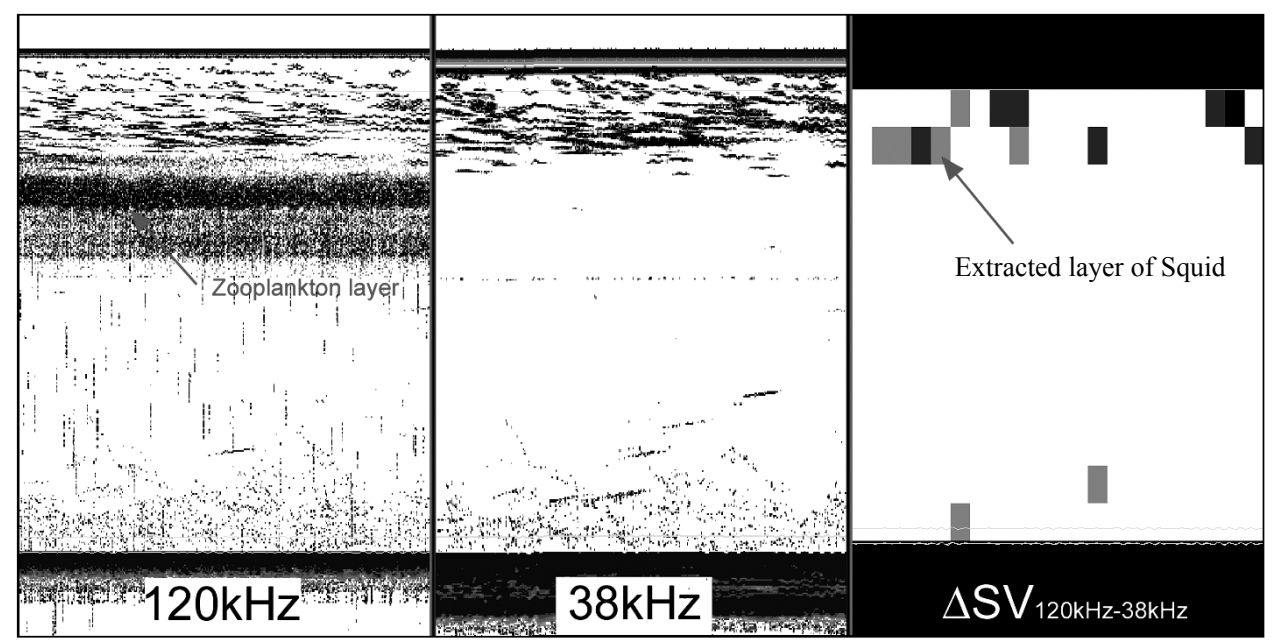

Fig. 6. An example of extracted layer for Japanese common squid using frequency difference method. 
다양한 회유성어족들이 분포하는 수층별 음 향자료로부터 오징어에 대한 음향신호를 분석 하기 위해DWBA모델에서 추정된 주파수 특성 을 기준으로 표본채 집시간대(야간)에 저 장된 에 코그램으로부터 음향산란층에 혼재되어 있는 오징어어군의 분리한 예를 Fig. 6 과 같이 나타내 었다. 그림에서 고주파수 $(120 \mathrm{kHz})$ 에코그램은 해 수면으로부터 동물플랑크톤이 존재하는 음향 산란층을 중심으로 상층부에 살오징어로 추정 되는 에코신호의 확인이 가능하였으며, 저주파 수 $(38 \mathrm{kHz})$ 에서는 주파수특성에 의해 음항산란 층은 확인되지 않으므로 음향산란이론모델에서 제시된 주퐈수 차의 값으로 최종적인 살오징어 의 음향신호를 추출할 수 있었다. 조사해역의 살 오징어의 적분층은 주간에는 저층주번에 분포 하고 야간에는 해 수면 상층부까지 분포하는 뚜 렷한 이 동특성을 나타내고 있었다.

과학어군탐지기의 다중 주퐈수에 의한 특정 산란체 에 대한 종 식별은 각각의 주파수 차에 의 한 체적후방산란강도 $(\mathrm{SV})$ 에 의해 결정된 적분

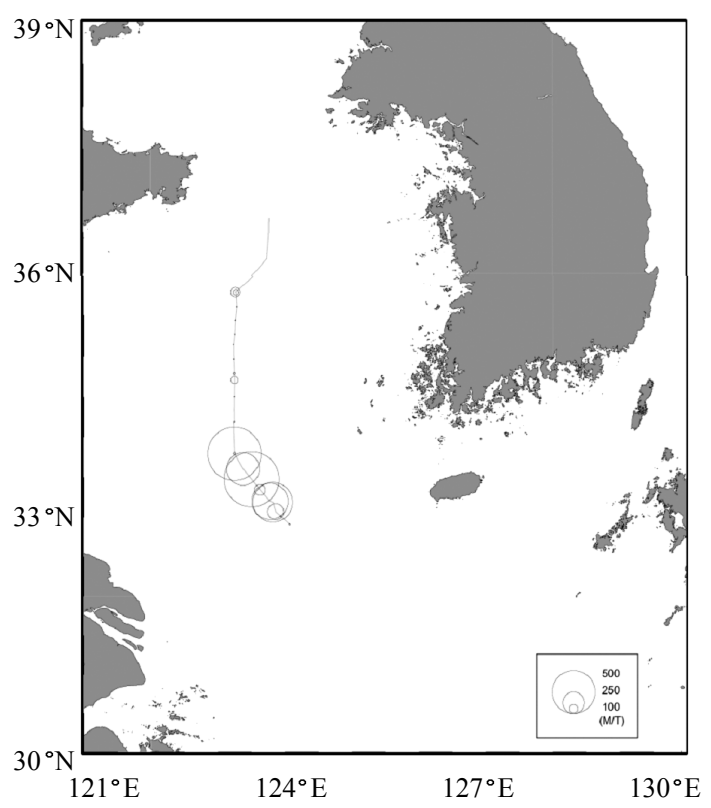

Fig. 7. Abundance distribution of Japanese common squid in survey area.
층을 추출하여 가상 에코그램이 만들어 주파수 차에 의 한 특정대상생물을 추출할 수 있다는 것 과 고주파수 에코그램의 음향산란층 하부에 기 록되어 있는 수중에서 발생되는 해양환경 잡음 을 처리할 수있어서 신뢰도 높은 음향신호의 분 석이 가능하다는 장점이 있다. 이 와같이 주퐈수 차에 의한 종 식별방법은 난바다곤쟁이류를 대 상으로 음향이론산란모델 과 유영행 동 패턴에 의해 동물플랑크톤이나 치어들로 수중에 혼재 되어있는 음항산란층내 난바다곤쟁 이류를 주파 수 차의 범위이내 적분층을 추출하여 분포밀도 를 추정하여 신뢰도를 향상시켰으며(Miyashita et al., 1997), 살오징 어에 대한 다중 주퐈수의 음 향산란특성을 파악하기 위한 지속적인 연 구가 되 고 있는 실정이다(Kang et al., 2005).

본 조사에서 수행한 한 - 중잠정조치수역의 이동조사라인에 대한 살오징어로 추정되는 음 향신호를 추출한 결과를 바탕으로 조사라인 의 $10 \mathrm{nmile}$ 당 살오징어의 분포밀도 추정 결과를 Fig. 7 과 같이 나타내었다.

한 - 중잠정 조치 수역의 위 도를 중심으로 북부 해역에서는 평균 $6.1\left(\mathrm{~g} / \mathrm{m}^{2}\right)$, 중부해역에서는 평 균 $5.5\left(\mathrm{~g} / \mathrm{m}^{2}\right)$, 남부해역에서는 평균 $85.0\left(\mathrm{~g} / \mathrm{m}^{2}\right)$ 의 분포를 나타내었으며, 조사해역의 평균 분포밀 도는 $32.2\left(\mathrm{~g} / \mathrm{m}^{2}\right)$ 로 추정되 었다.

한편, 조사해역에서 표본으로 채집한 살오징 어가 분포하는 평균체장의 변동가능성이 있으며 유영 자세각의 변화에 따른 후방산란단면적의

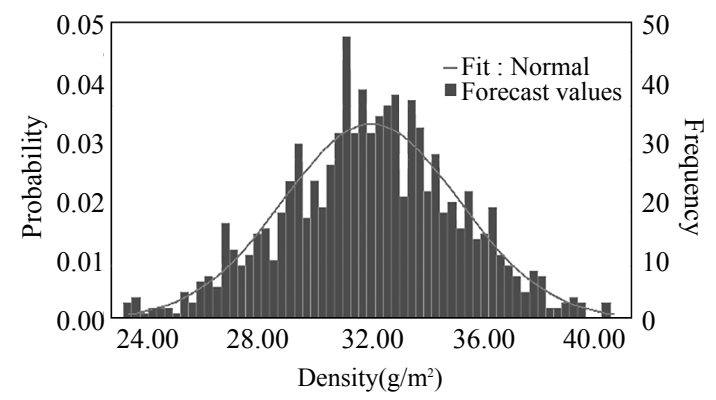

Fig. 8. The result of Monte Carlo simulation according to uncertainty in abundance of Japanese common squid. 
변동가능성을 고려할 수 있다. 따라서, 살오징어 의 평균체 장 및 후방산란단면적의 불확실성을 고려 하여 몬테카를로 시뮬레이션을 실시 하였는 데, 조사해역의 분포밀도의 최대값과 최소값을 포함할 수 있도록 평균값을 중심으로 $\pm 5 \%$ 의 범 위로 설정하였다. 그 결과, 최소 $23.1\left(\mathrm{~g} / \mathrm{m}^{2}\right)$ 에서 최대 $41.4\left(\mathrm{~g} / \mathrm{m}^{2}\right)$ 까지 범위 로 추정 되었다.

추가적인 분석방법으로는 살오징어의 적분층 신뢰도 수준을 높이기 위하여 2 개 이상의 다양 한 주퐈수 분석의 비교를 통해 정도 높은 살오징 어의 적분층을 추출하고, 다년간의 음향자로 처 리를 바탕으로 황해 한 - 중잠정조치수역에 분 포하는 살오징어의 자원량의 변동을 검토할 예 정이다. 이러한 분석방법은 향후 우리나라넓은 해역에 분포하고 있는 오징어의 분포밀도를 퐈 악할 수 있을 것으로 판단되며, 실제 음향자원평 가에 있어서 해역특성에 맞는 생태학적인 특성 (특히, 군집성의 유무, 주야이 동패턴 등)을 고려 하여야 할 것이다. 또한, 주파수 특성에 대한 다 양한 분포 어종에 대한 정보를 토대로, 보다 정 도 높은 어종 식별의 분석이 필요하므로 과거 주 요 어족자원에 대한 음향산란특성에 관한 연 구 자료를 바탕으로 데이터베이 스화하여 대 상어 족 자원의 직 접자원 량 기법의 확립이 필요하다고 판단된 다.

\section{결 론}

한 - 중 잠정조치수역 내 자원조사 기간동안 다양한 회유성 어족들이 분포하는 수층별 음향 자료로부터 오징어에 대한 음향산란신호를 규 명하기 위해 DWBA 모델을 이융하여 외투장 (M.L)을 기준으로 전장에 대한 2 주퐈수 특성을 비교하였으며, 이론값을 계산하기 위하여 필요 한 유영자세각의 확률밀 도함수는 $-17.7^{\circ} \pm$ $12.7^{\circ}$ 를 적용하였고, 체내 음속비(h) 와 밀도비 $(\mathrm{g})$ 를 각각 1.041 및 1.029 의 값을 대입하여 각 주 파수별 체장에 대한 평균 $\mathrm{TS}$ 값을 추정하었다. 그 결과, 고주파 $(120 \mathrm{kHz})$ 와 저주파 $(38 \mathrm{kHz})$ 에 대
한 후방산란강도의 값이 약 $-0.01 \mathrm{~dB}-0.64 \mathrm{~dB}$ 의 범위로 설정하여 살오징어의 에코신호를 추 출하었고 어획량이 많은 시간대에 분포하는 오 징 어에 대한 음향신호의 분리 가능성을 확인하 였다. 그 결과, 조사해역에 분 포하는 살오징어의 평 균밀 도는 $32.2\left(\mathrm{~g} / \mathrm{m}^{2}\right)$ 로 추정되 었으며, 체 장 및 유영자세각의 불확실성을 고려한 몬테카를로 시 뮬레이션 의 추정결과, 최소 $23.1\left(\mathrm{~g} / \mathrm{m}^{2}\right)$ 에서 최 대 $41.4\left(\mathrm{~g} / \mathrm{m}^{2}\right)$ 까지 범위로 분포하고 있는 것으로 추정되었다. 이러한 결 과는 다중주퐈수기법에 의한 목표어종의 음향신호를 분리하여 주야 수 층별 분포에 대한 생태적인 정보와 조사라인의 계획에 따라 우리나라 주변해역의 현존량 추정 에 적 용될 것으로 판단된 다.

\section{사 사}

본 연구는 국립수산과학원(선 망용 집어시스 템 개발, RP - 2009 - FE - 009)의 지원에 의해 수 행 되었으며, 실험에 적 극적으로 협조하여 주신 국립수산과학원 시험조사선 탐구1호 우병하 선 장님과 김용준 항해장님을 비롯한 선 박직 원 분 들께 감사드립니다. 끝으로 본 논문을 사려 깊게 검토하여 주신 심사위원님들과 편집 위원님께 감사드립니다.

\section{참고문헌}

Goss, C., D. Middleton and P. Rodhouse, 2001. Investigations of squid stocks using acoustic survey methods. Fish. Res., 54, 111 - 121.

Kang, D.H., D.J. Hwang, T. Mukai, K. Iida and K.H. Lee, 2004. Acoustic target strength of live Japanese common squid(Todarodes pacifica) for Applying biomass estimation. J. Kor. Fish. Soc., 37(4), 345 353.

Kawabata, A., 2005. Target strength measurements of suspended live ommastrephid squid, Todarodes pacifica, and its application in density estimations. Fisheries Science, 71, 63 - 72.

Kang, D.H., T. Mukai, K. Iida, D.J. Hwang and J.G. 
Myoung, 2005. The influence of tilt angle on the acoustic target strength of the Japanese common squid (Todarodes pacifica). ICES J. of Mar. Sci., 62, $779-789$.

Kang, D.H., K. Iida, T. Mukai and J.M. Kim, 2006. Density and sound speed contrasts of the Japanese common squid(Todarodes pacifica) and their influence on acoustic target strength. Fish. Sci., 72, $728-736$.

Kang, M, M. Furusawa and K. Miyashita, 2002. Effective and accurate use of difference in mean volume backscattering strength to identify fish and plankton. ICES J. Mar. Sci., 59, 794 - 804.

Lee, D.J., 2005. Fish length dependence of acoustic target strength for 12 dominant fish species caught in the Korean waters at $75 \mathrm{kHz}$. J. Kor. Soc. Fish. Tech., 41(4), $296-305$.

Miyashita, K, I. Aoki, K. Seno, K. Taki and T. Inagaki, 1997. Acoustic identification of isada Krill, Euphausia pacifica Hansen, off the Sanriku coast, north - eastern Japan. Fish. Oceanogr., 6, 266 - 271.
McGehee, D.E., R.L. O’Driscoll and L.V.T. Martin, 1998. Effects of orientation on acoustic scattering from Antarctic Krill at $120 \mathrm{kHz}$. Deep - Sea Res., 45, 1273 - 1294.

Mukai, T., K. Iida, K. Sakaguchi and K. Abe, 2000. Estimations of squid target strength using a small cage and theoretical scattering models. In: The Proceedings of the JSPS.DGHE International Symposium on Fisheries Science in Tropical Area. Fisheries Science in Tropical Asia, Bogor, Indonesia, $135-140$.

NFRDI, 2005. Ecology and fishing ground of coastal inshore fishery resources. National Fisheries Research \& Development Institute, pp. 355 - 370.

SonarData, 2000. SonarData EchoView User Guide. SonarData Tasmania Pty. Ltd., pp. 1 - 60.

Watkins, J.L. and A.S. Brierley, 2002. Verification of the acoustic techniques used to identify Antarctic krill. ICES J. Mar. Sci., 59, 1326 - 1336.

2009년 7 월 27 일 접수

2009 년 8 월 19 일 1 차 수정

2009년 8 월 19 일 수리 